\title{
Ambientes virtuais de aprendizagem: desafios de uma escola de governo
}

Andréa Filatro e Natália Teles da Mota

\section{Introdução}

Em mais de 20 anos de atuação, a Escola Nacional de Administração Pública (ENAP) vem consolidando sua missão de desenvolver competências de servidores públicos para aumentar a capacidade de governo na gestão de políticas públicas por meio da oferta de diferentes eventos de aprendizagem, como cursos, oficinas, palestras e especializações.

Referência no campo da formação e da capacitação continuada de servidores públicos, a Escola busca continuamente aprimorar seu ambiente tecnológico, a fim de sustentar o crescimento sistemático de seus serviços e capacitações. A incorporação de tecnologias contemporâneas a seus eventos de aprendizagem não só contribui para um crescimento quantitativo, mas também torna o processo de ensino e aprendizagem mais dinâmico, flexível, contextualizado, empreendedor e inovador. Isso significa ampliar os espaços e tempos de aprendizagem e concretizar uma pedagogia de protagonismo, que valoriza o sujeito como autor de sua história. 
A decisão de ampliar as possibilidades educacionais da Escola por meio do uso mais intenso de tecnologias de informação e de comunicação implica prepará-la para lidar com contextos dinâmicos e mutáveis. O desafio maior é o de se evitar a rápida obsolescência dos esforços em função da fluidez tecnológica do contexto em que estamos inseridos (ENAP, 2006, 2008, 2010; Amaral, 2008).

Várias são as inovações tecnológicas que intentam dominar o mercado no futuro próximo da educação - entre elas, podemos citar as apontadas pelo 2010 Horizon Report (Educause, 2010) para os próximos quatro a cinco anos: computação móvel $^{1}$, conteúdos abertos ${ }^{2}$, livros eletrônicos, realidade aumentada ${ }^{3}$, computação baseada em gestos ${ }^{4}$, análise visual de $\operatorname{dados}^{5}$.

A decisão sobre qual plataforma tecnológica adotar, contudo, repousa sobre um modelo de gerenciamento de aprendizagem e de conteúdos que requer considerações em diversos níveis (metodológicos, tecnológicos e jurídicos).

No campo da metodologia de ensinoaprendizagem, as principais tendências apontam para práticas pedagógicas mais contextualizadas (socioconstrutivismo e abordagem situada) e para a perspectiva andragógica $^{6}$, focada exclusivamente na educação de adultos. Novos conceitos, como a heutagogia ${ }^{7}$ e o conectivismo ${ }^{8}$, emergem na tentativa de teorizar as transformações educacionais em curso, muitas delas formadas fora das instituições de ensino convencionais (HASE \& KENYON, 2000; Siemens, 2004).

O desafio logístico de ofertar oportunidades de aprendizagem a qualquer hora, em qualquer lugar e por quaisquer meios, inclusive móveis e tridimensionais, as novas formas de produzir, armazenar e acessar informações, e a redefinição de papéis e atores envolvidos no processo educacional configuram uma nova lógica de ensino-aprendizagem que precisa ser considerada na decisão por um ou outro ambiente virtual de aprendizagem (AvA) .

Ao considerar a linha evolutiva para esses sistemas identificada por SIQUEIRA (2005) - que vai dos gerenciadores de ferramentas (LMS), passando pelos gerenciadores de conteúdos (LCMS), para chegar aos mais recentes dedicados ao gerenciamento de atividades (LAMS) e à personalização total da aprendizagem (PLE) -, delineia-se uma segunda geração de ambientes virtuais de aprendizagem (Vle 2.0 ${ }^{10}$. Esses sistemas são capazes de integrar-se não apenas com ferramentas isoladas e fechadas, mas com todo um conjunto de dados, objetos e funcionalidades (Weller, 2007). Baseiam-se em uma nova lógica computacional, pautada em padrões abertos de programação e interoperabilidade técnica, que precisam ser considerados na contratação de uma plataforma tecnológica.

Par e passo com essa evolução metodológica e tecnológica, questões relativas à propriedade intelectual se revelam críticas no que diz respeito ao debate "software livre" versus "software proprietário" 11 e também à autoria colaborativa, ao reuso e ao compartilhamento institucional de recursos produzidos por meio dessas tecnologias.

Além disso, demandas que não se restringem apenas à aquisição de produtos tecnológicos, mas abrangem também serviços intrínsecos a eles, manifestam a necessidade de uma nova lógica de contratação e de gestão de contratos que considere a complexidade inerente a contexto tão inovador. 


\section{Situação atual da ENAP e cená- rios prospectados}

Mesmo realizando aproximadamente 34 mil capacitações/ano em mais de 150 cursos voltados à formação do servidor público - entre educação continuada e especialização, nas modalidades mista, presencial e a distância - e contando com um fluxo mensal de cerca de 100 mil consultas às suas bases documentais (dados de julho de 2010), a ENAP experimenta hoje uma defasagem tecnológica, se consideradas as tendências externas delineadas anteriormente e as demandas internas por crescimento.

Nesse sentido, está surpreendentemente alinhada com instituições parceiras nacionais e internacionais que, insatisfeitas com a base tecnológica ora disponível para as ações de aprendizagem e gestão de conhecimento, necessitam simultaneamente inovar e crescer.

A partir das demandas explicitadas pelas diversas áreas da ENAP, foram prospectados - entre as inúmeras possibilidades - três cenários que combinam ênfases metodológicas e níveis de apropriação das TIC pela Escola, para apoiar a definição do tipo de plataforma tecnológica (produtos e serviços) a ser adotada nos próximos anos.

Para isso, foram consideradas as transformações de natureza técnica, pedagógica e produtiva que traçam uma linha evolutiva na adoção de tecnologias em educação (Filatro, 2008; Litto \& Formiga, 2008). Combinada a uma estimativa de expansão qualitativa e à respectiva ampliação do nível de absorção pela Escola, consideramos que essa linha evolutiva abriga três cenários básicos representados na Figura 1 e descritos mais detalhadamente a seguir:

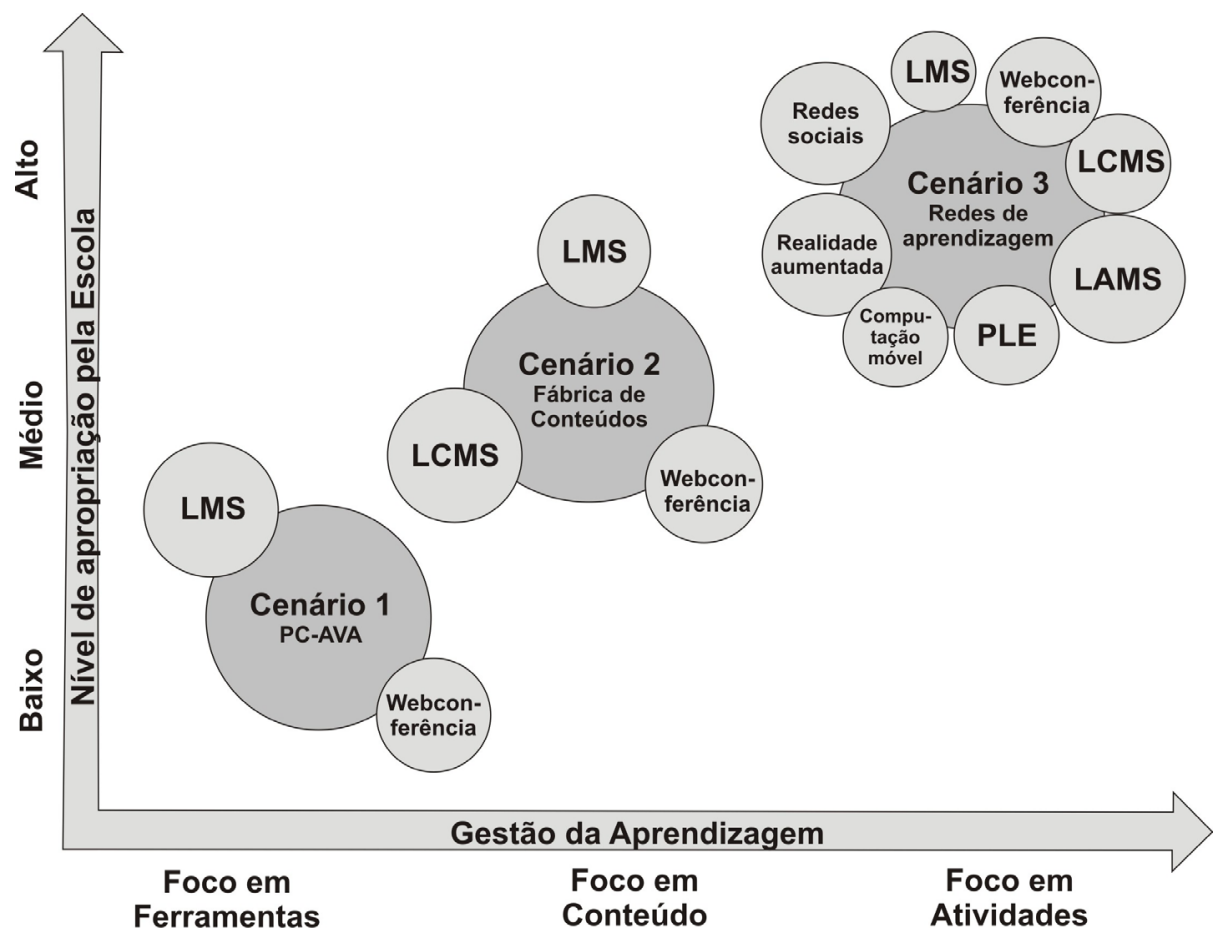

Fonte: Elaboração própria.

Figura 1: Cenários prospectados no âmbito do GT-AVA e suas respectivas ênfases 


\section{Cenário 1}

O Cenário 1, que enfatiza o acesso via computador pessoal (PC) a ações e eventos concentrados em um ambiente virtual de aprendizagem fechado (AVA), mantém o foco atual de utilização de tecnologias nas ações da ENAP, buscando aperfeiçoamentos no que tange à incorporação do recurso de videoconferência, bem como à solução de questões de infraestrutura e atendimento a demandas internas da Coordenação-Geral de Educação a Distância (CGEAD), configurando-se uma gestão mais rigorosa do contrato de fornecimento de serviços de manutenção, suporte ao usuário e atualização.

O Sistema de Gestão de Aprendizagem (Learning Management System - LMS) em que esse cenário está apoiado restringe-se a centralizar e simplificar a administração e a gestão dos programas educacionais, permitindo matrícula de estudantes, armazenamento e consulta a informações, publicação de arquivos em diferentes formatos, comunicação síncrona e assíncrona entre usuários, criação e aplicação de testes, rastreamento de dados e geração de relatórios sobre o progresso dos participantes.

É, portanto, um modelo focado no gerenciamento de ferramentas, no qual a implementação de conteúdos no ambiente on-line se dá de maneira artesanal. Há descentralização na produção e no armazenamento de conteúdos, sem aderência a padrões de programação, descrição, busca e interoperabilidade técnica.

As equipes de EAD (interna e externa) realizam manualmente adaptações necessárias no caso de públicos diferenciados, correção de erros, atualização de versões, modificação de interfaces etc. A médio e longo prazo, representa uma oportunidade de crescimento qualitativo da EAD, mas em baixa escala.

Por outro lado, com o apoio de ferramentas integradas em um LMS convencional, as diferentes estratégias pedagógicas usadas nos cursos presenciais são facilmente transportadas (e até expandidas, como é o caso das comunidades virtuais) para o ambiente digital, requerendo para isso apenas capacitação dos docentes e das equipes responsáveis por eventos presenciais com relação ao uso dessas tecnologias. Entretanto, nesse cenário, o uso dos ambientes virtuais de aprendizagem permanece quase restrito à oferta de cursos a distância. O uso de comunidades virtuais em apoio a eventos presenciais de aprendizagem funciona mais como repositório ${ }^{12}$ de arquivos do que como ambiente de discussão, integração e construção coletiva de conteúdos.

Esse é, em boa medida, o modelo adotado pela ENAP hoje, ressalvando as dificuldades no uso de chats e webconferências, recursos críticos para a efetividade da relação aluno-tutor. O mesmo público atendido atualmente pode beneficiar-se do desenvolvimento natural dos recursos tecnoeducacionais, por exemplo, pela atualização de novas versões do LMS e integração com computação móvel e sem fio, o que implicaria uma sofisticação da oferta, provavelmente a um custo mais elevado por aluno.

\section{Cenário 2}

O Cenário 2 dá maior destaque à gestão profissional de conteúdos educacionais e genéricos, apoiando-se no modelo de produção "fábrica de conteúdos" e na organização desses conteúdos por meio de repositórios de recursos e objetos de aprendizagem ${ }^{13}$. 
O foco da disponibilização de conteúdos se traduz em uma ênfase considerável nas mídias de entrega, que requerem uma produção de profissionais, especializada e geralmente cara, segundo processos padronizados, que permitem o desenvolvimento de soluções educacionais em larga escala. Por esse motivo, exige-se grande atenção ao equilíbrio custobenefício.

O Cenário 2 compreende, além dos recursos mencionados no Cenário 1 (LMS e webconferência), a utilização do conceito de sistema de gerenciamento de conteúdos (Learning Content Management System - LCMS), que fornece os meios para armazenar, indexar, recuperar, referenciar e reutilizar conteúdos de aprendizagem de forma mais eficiente, visando à gestão, organização e ao reaproveitamento parcial ou integral de conteúdos e reduzindo, assim, os esforços de desenvolvimento.

Além dos LMS para gestão de acessos e registro de participações, os gerenciadores de conteúdo (LCMS) são adotados por oferecerem mecanismos de indexação baseados em metadados ${ }^{14}$, e repositórios para armazenamento centralizado de conteúdos institucionais. O acervo é disponibilizado a desenvolvedores, conteudistas, educadores e alunos para maior utilização e reutilização.

Esse modelo de elaboração de conteúdos e entrega on-line permite um crescimento do número de servidores atendidos, o que pode representar uma estratégia de expansão quantitativa, inclusive no que diz respeito à ampliação de uso da plataforma em apoio aos cursos presenciais. O uso do ambiente virtual de aprendizagem tende a extrapolar os cursos a distância e se expandir para outras áreas da Escola.
Ao possibilitar a integração de dados e a interoperabilidade de recursos, estende o escopo da solução tecnológica para atender a demandas por otimização dos esforços de construção e disseminação de documentos e informações relativos a eventos de aprendizagem comuns a diferentes áreas da ENAP, além de favorecer o compartilhamento de cursos e eventos de aprendizagem pela Rede Nacional de Escolas de Governo.

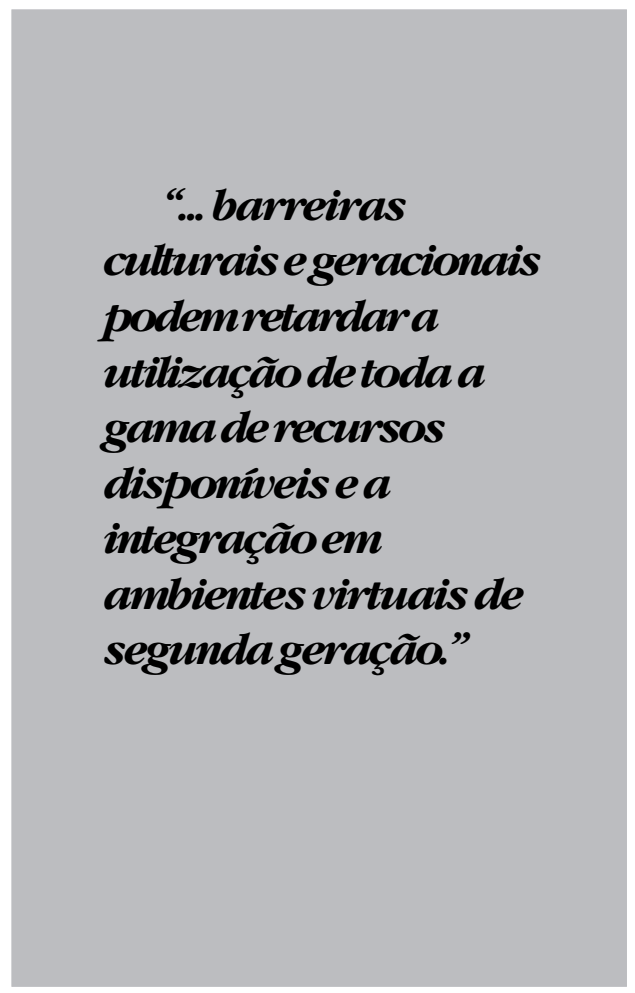

\section{Cenário 3}

O Cenário 3 tem foco em atividades de aprendizagem personalizadas, baseadas em situações didáticas contextualizadas. Para isso, adere plenamente à web $2.0^{15}$, à computação móvel e sem fio, às redes sociais e inovações como realidade aumentada e afins, em larga escala. 
LMS de segunda geração permitem acoplamento de conteúdos gerenciados por LCMS e de eventos e atividades de aprendizagem planejadas por Learning Activity Management System - LAMS (softwares para planejamento pedagógico). Esses sistemas de gerenciamento de atividades de aprendizagem possibilitam o desenho e execução de unidades de aprendizagem estruturadas a partir de atividades individuais e coletivas, com base na ideia de que o que interessa é o que as pessoas fazem com os conteúdos educacionais, e o que as ferramentas como e-mail, fórum, chat etc. permitem que as pessoas façam, a fim de que a aprendizagem ocorra.

Os produtos resultantes são armazenados em repositórios acessíveis a toda a comunidade de aprendizagem envolvida, configurando-se inclusive um espaço de colaboração interinstitucional para construção e compartilhamento de cursos e conteúdos.

Nesse cenário, o uso dos ambientes virtuais se dá de forma sistêmica por todas as áreas da Escola, expandindo-se externamente em apoio a ações educacionais com parcerias nacionais e internacionais.

Os alunos acessam os recursos por meio de seus próprios Personal Learning Environment-PLE (ambientes virtuais personalizados, organizados pelos próprios alunos e baseados fortemente no que se convencionou chamar de web 2.0), nos quais definem e atualizam suas preferências tecnológicas e metodológicas, optando, por exemplo, por estudar sozinhos ou de forma colaborativa, não apenas em um curso específico, mas em qualquer ação de aprendizagem realizada no decorrer de sua vida educacional. Esses dados de perfil e histórico individual são intercambiados com o sistema de gerenciamento da aprendizagem institucional no momento em que o aluno se inscreve em um curso ou unidade de estudo. Da mesma forma, dados de desempenho do aluno em situações didáticas específicas retroalimentam seu portfólio individual, além de ficarem armazenados no ambiente institucional.

Pela provisão de serviços de alta qualidade a um custo menor (por exemplo, pela substituição de redução de pacotes complexos de software por softwares disponíveis em "nuvens"16 e pelo planejamento contextualizado e uso compartilhado dos recursos - desde que garantidas, em ambos os casos, a privacidade, a manutenção e o resgate das informações), esse modelo de produção permitiria um crescimento em escala do número de servidores atendidos.

Essa perspectiva pressupõe descolamento do padrão PC-AVA, presente nos Cenários 1 e 2, alargando as possibilidades de construção de redes de aprendizagem, de ensino e de parcerias. Pela natureza inerentemente inovadora, implica ações continuadas e parcerias para pesquisa e desenvolvimento, reforçando o papel de liderança da ENAP no cenário nacional e internacional de formação do servidor público.

Há de se considerar, contudo, que, por ser um modelo bastante inovador, muitas das funcionalidades necessárias para dar suporte a esse cenário ainda não estão completamente disponíveis ou encontramse em caráter experimental. Portanto, para a efetividade dessa análise, elencamos algumas funcionalidades já plenamente operacionalizáveis que, utilizadas em conjunto, proporcionam o mínimo necessário para a adoção do cenário proposto.

Outro ponto a ser destacado é a necessidade de uma curva de aprendizagem relativamente grande antes da utilização do ferramental de planejamento pedagógico pelos docentes e pela equipe de 
coordenação. Além disso, barreiras culturais e geracionais podem retardar a utilização de toda a gama de recursos disponíveis e a integração em ambientes virtuais de segunda geração.

Nesse cenário arrojado, a ENAP assumiria um papel mais pró-ativo, na medida em que nem todas as questões envolvidas - como direitos autorais na era digital estão encaminhadas. Isso significaria arcar com o ônus do pioneirismo, em especial no cenário nacional, capitaneando mudança de paradigma não apenas no âmbito tecnológico, mas principalmente de natureza cultural.

\section{Considerações quanto aos cenários}

Independentemente da decisão sobre o cenário a ser adotado, algumas considerações se fazem necessárias à atenção de gestores e tomadores de decisão para que a solução tecnológica adotada possa corresponder, em médio ou longo prazo, às demandas metodológicas, tecnológicas e jurídicas emergentes.

\section{Considerações de natureza meto- dológica}

Uma das questões mais críticas ao decidir que tipo de plataforma tecnológica adotar remete aos perfis dos públicos-alvo atendidos pela instituição. Embora distintos, esses públicos refletem diferenças profundas nas concepções sobre o que significa aprender e ensinar, que se traduzem em abordagens pedagógicas mais autênticas e contextualizadas e em práticas andragógicas e heutagógicas emergentes.

De um lado, encontram-se servidores formados por um tipo de escolarização tradicional, desafiados a aprender continuamente e a rever suas práticas profissionais para adequar-se às novas demandas de trabalho, em boa parte capitaneadas pela adesão maciça a soluções tecnológicas, por exemplo, na digitalização de processos, na comunicação por meios eletrônicos e na criação e manutenção de comunidades virtuais de prática, para citar algumas. De outro lado, observam-se novos ingressantes nas carreiras públicas que apresentam perfil mais próximo da chamada "geração digital" (TАРссотт, 1999), nascida e criada em uma cultura midiatizada, globalizada e mundialmente conectada, em que aprender é uma atividade constante, realizada de forma individual e coletiva, a partir e por meio do grande acervo de recursos informacionais, humanos e ferramentais provido pela web.

É importante realçar que, embora a realidade de boa parte do serviço público seja de restrições tecnológicas e a exclusão digital persista entre algumas instituições e servidores, a disposição para o avanço tecnológico e pedagógico se relaciona a um contexto organizacional mais amplo, favorável à mudança de mentalidade e à adoção de tecnologias e recursos mais avançados.

Nesse sentido, ambos os perfis citados impulsionam e reivindicam formas diferenciadas de aprender, distintas da oferta de educação tradicional e em grande medida baseadas em maior autonomia por parte do aluno sobre o que e como aprender, em convergência de mídias para criar e apresentar conteúdos e em possibilidade de personalizar percursos didáticos e modalidades de aprendizagem (a distância, presenciais, mistas), segundo necessidades particulares e temporais.

Acrescente-se que essa mudança de postura reflete-se também no corpo docente, que vislumbra as possibilidades de planejar e apresentar soluções de aprendizagem de forma mais colaborativa, 
beneficiando-se mais ativamente de ferramentas e espaços virtuais voltados à organização e ao compartilhamento do trabalho pedagógico.

A evolução dos sistemas para aprendizagem em meio eletrônico - de LMS focados na gestão de ferramentas para LCMS focados na gestão de conteúdos; para LAMS focados na gestão de atividades de aprendizagem; e, por fim, para os PLE focados na personalização dos ambientes de aprendizagem - reforça a compreensão de que a educação - mesmo aquela totalmente mediada por tecnologias, como é o caso da educação mediada por tecnologias totalmente a distância - implica ação individual e interação entre pessoas.

Isso equivale a dizer que apenas ferramentas - ou apenas conteúdos - não traduzem a complexidade dos processos de ensino-aprendizagem; portanto, qualquer solução tecnológica adotada por uma instituição não pode se limitar à aquisição de produtos (hardware, software, rede), mas deve também e principalmente estar voltada à contratação de serviços (manutenção, atendimento ao usuário, planejamento e desenvolvimento de conteúdos, atividades e ferramentas, capacitação da equipe).

\section{Considerações de natureza tecno- lógica}

$\mathrm{Um}$ requisito que emerge da análise de tendências tecnológicas é a compreensão da natureza dinâmica, inovadora e mutante das tecnologias aplicadas à educação, e, por consequência, da necessidade de gestão profissional e estratégica dos diferentes aspectos envolvidos.

As inovações tecnológicas anunciadas colocam em uma nova perspectiva o modelo ora predominante de transmissão de informações de um para muitos (broadcasting), pois possibilitam formas diferenciadas de criação, armazenamento, distribuição, acesso, manuseio e reutilização de conteúdos, eventos e atividades. Isso faz com que sejam extrapolados os limites da sala de aula convencional, seja pelo acesso em sala de aula a um repositório mundial de conteúdos e pessoas, como é a web, seja pela possibilidade de consultar esses conteúdos e pessoas de qualquer lugar, em qualquer hora, por meio de dispositivos móveis e sem fio. A hierarquia professoraluno (na medida em que os usuários deixam de ser apenas consumidores de informações e se tornam eles mesmos produtores) e até mesmo o próprio conceito de sistema da informação (com a integração entre diferentes softwares, dispositivos e informações) são também reformulados nesse novo contexto.

A multiplicidade de soluções disponíveis, cada qual com vantagens e desvantagens específicas, torna mandatória a adesão a padrões tecnológicos abertos e universais, a fim de assegurar a capacidade de acoplagem a novas ferramentas, a reutilização de recursos e a interoperabilidade de dados.

Destaca-se a importância de cultivar uma filosofia de "abertura", que possibilite a criação e utilização de recursos abertos (conteúdos, metodologias e ferramentas). Isso reforça a necessidade de um planejamento integrado para as áreas de educação, gestão do conhecimento e tecnologia, que considere as interfaces entre as áreas e as possibilidades de compartilhamento de hardware, software e redes.

Também se faz desejável a provisão de serviços profissionais por empresas certificadas internacionalmente, a fim de garantir a estabilidade do sistema, a qualidade dos serviços prestados e a constante atualização tecnológica necessária à evolução incessante das tecnologias. 
Considerações de natureza jurídica

Dos cenários elencados para contratação de uma plataforma tecnológica advirão um ou mais contratos administrativos. Estabelecer condições (cláusulas) e fiscalizar seu cumprimento requer servidor devidamente qualificado, preparado para a missão e atento a algumas premissas básicas:

- Definição clara e transparente das regras e condições de contratação e fiscalização do contrato pela instituição, possibilitando julgamento objetivo, célere e eficiente.

- Definição do objeto de contratação e identificação das ofertas do mercado fornecedor por uma equipe técnica formada por profissionais da área de TI, das áreas de ensino demandantes, da área de contratos e outras afins, sendo possível a realização de consulta pública com vistas a promover o debate sobre as especificações e características de determinado bem ou serviço a ser contratado, em estrita obediência aos princípios da isonomia e promoção da competitividade.

- Designação e preparação de gestor ou comissão gestora do contrato para acompanhamento e fiscalização sistemática, a fim de garantir atendimento às exigências e requisitos previamente estabelecidos e aplicação de sanção administrativa pela instituição contratante, se cabível.

- Caso seja feita opção por um modelo de licitação que implique contratação de diversas empresas, cada uma oferecendo determinada ferramenta ou tecnologia, há necessidade de atentar para as questões de interoperabilidade. Não há garantias no mercado de que a comunicação entre tecnologias diferentes, especialmente as mais recentes, ocorra de forma transparente ao usuário. Nesses casos, o estudo pormenorizado dos requisitos de interoperabilidade a serem definidos no documento de licitação contribui para minimizar os problemas na fase posterior de prestação do serviço.

\section{Considerações de natureza econô- mica \\ Os cenários 1, 2 e 3 não são excludentes; pelo contrário, complementam-se ao espelhar a evolução tecnológica e metodológica, descrita neste artigo, bem}

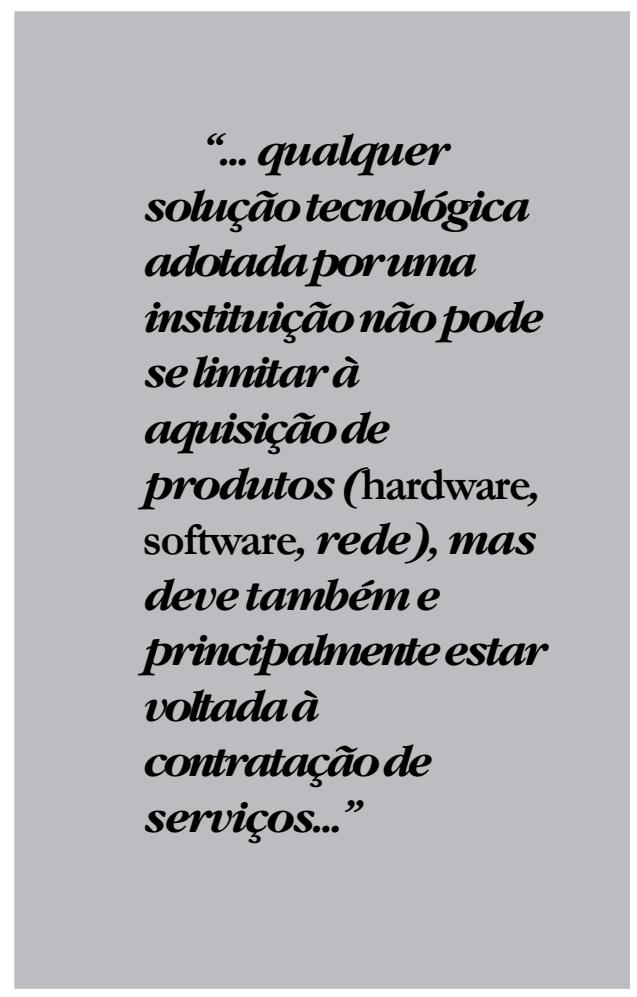

como níveis de apropriação das TIC para construção e oferta de soluções educacionais, sejam elas presenciais apoiadas por tecnologias, mistas ou totalmente a distância.

O cenário 1 é o que mais se aproxima das práticas em curso e, ainda assim, não está plenamente consolidado entre as instituições que optam por incorporar tecnologias às ações educacionais. 
O cenário 2 é bastante factível no momento atual e está relativamente absorvido pela comunidade de EAD nacional, especialmente nas ações de educação corporativa privada. Representa um avanço na produção de eventos de aprendizagem, uma vez que permite desenhos didático-pedagógicos mais elaborados, implicando uma mudança efetiva no papel docente, de principal fonte de transmissão de conhecimentos a mediador e orientador dos aprendizes.

Com as demandas por atendimento em larga escala no curto prazo, e as especificações técnicas e metodológicas levantadas neste estudo, recomenda-se a adoção do Cenário 2 para a oferta de alguns cursos, visando a atender a outras áreas, em especial a área de Comunicação e Pesquisa, e ampliar as parcerias para compartilhamento de cursos e recursos no âmbito da Rede Nacional de Escolas de Governo e outras instituições parceiras. Essa recomendação se aplica especialmente a uma projeção de público total atendido próxima ou acima de 1 mil alunos.

Ressalta-se que essa recomendação representa uma etapa intermediária em direção ao cenário 3, o qual requer esforços mais significativos não apenas para integração das ferramentas aqui descritas, mas também para formação e desenvolvimento dos profissionais internos que levarão a cabo sua implementação.

Embora não se observe a mesma redução de custos em função do número de usuários atendidos como acontece no Cenário 2, o Cenário 3 representa uma evolução qualitativa em termos de materiais apresentados em diversas mídias e do tipo de interação entre todos os participantes, justificando sua adoção futura.

(Artigo recebido em abril de 2012. Versão final em março de 2013).

\section{Notas}

${ }^{1}$ Computação móvel: paradigma computacional advindo da tecnologia de rede sem fios e dos sistemas distribuídos, em que são utilizados dispositivos móveis, tais como celulares, PDAs etc.

${ }^{2}$ Conteúdos abertos: em inglês, open content. Qualquer tipo de trabalho criativo (por exemplo, artigos, imagens, áudio, vídeo etc.) pode ser utilizado ou modificado sem (ou com poucas) restrições legais e distribuído num formato que, explicitamente, permite a cópia da informação.

${ }^{3}$ Realidade aumentada: tecnologia que possibilita o enriquecimento do ambiente físico com elementos virtuais, criando um ambiente misto em tempo real. Os elementos podem variar de simples projeções sobre objetos físicos a projeções holográficas de personagens 3D que interagem com pessoas reais.

${ }^{4}$ Computação baseada em gestos: refere-se ao conjunto de dispositivos e softwares que reconhecem, interpretam e reagem a movimentos corporais controlados por movimentos naturais dos dedos, mãos, braços e corpo, reduzindo a necessidade de aprender a interagir com os computadores, que passam a reagir aos comportamentos humanos.

${ }^{5}$ Análise visual de dados: campo emergente que combina estatística, mineração de dados (data mining) e visualização que permite a qualquer pessoa navegar, exibir e compreender conceitos e relacionamentos complexos em grandes conjuntos de dados. Possibilita a descoberta e a compreensão de padrões por meio de interpretação visual e manipulação de modelos em tempo real. 
${ }^{6}$ Andragogia (andros = adulto + agogus = guiar, conduzir, educar para a "formação de adultos"): conjunto de teorias e práticas educacionais que considera a maturidade biológica dos aprendizes, juntamente com seu rol de experiências acumuladas, psicológicas, afetivas, profissionais e culturais, que implicam maior grau de autonomia nas decisões sobre como estudar.

${ }^{7}$ Heutagogia $($ heuta $=$ próprio + agogus $=$ guiar, conduzir, educar $)$ : conjunto de teorias e práticas educacionais ainda em formação que pressupõe elevada (ou absoluta) autonomia por parte de quem aprende, não importa a faixa etária ou a formação acadêmica em questão, no cenário moderno em contínua transformação, que exige flexibilidade e proatividade para atuar em espaços de convivência e trabalho carregados de incertezas.

${ }^{8}$ Conectivismo: teoria proposta por Siemens (2004) para o cenário de uma sociedade totalmente digital, na qual aprender é um processo de conectar fontes de informação especializadas.

${ }^{9}$ Ambiente virtual de aprendizagem (AVA) é a expressão preferida pelos educadores para enfatizar menos o monitoramento e o controle, e mais a ação e a interação entre as pessoas, em uma espécie de sala de aula on-line.

${ }^{10}$ VLE 2.0, sigla em inglês para Virtual Learning Environment 2.0 (ambiente virtual de aprendizagem de segunda geração): refere-se ao conjunto de aplicativos interoperantes no qual ferramentas de desenho e exibição permitem que conteúdos e atividades educacionais sejam reutilizados e recombinados de acordo com as necessidades e interesses do aluno.

${ }^{11} \mathrm{O}$ software livre fundamenta-se na socialização sistematizada dos códigos-fonte e da documentação dos programas em repositórios internacionais livres, utilizados para controlar e manter o desenvolvimento de soluções abertas. É pautado por um modelo horizontal e descentralizado de desenvolvimento, em que qualquer usuário da internet pode atuar na tradução, no design de interface gráfica, na codificação, nos testes e na programação. Já a distribuição de softwares proprietários é pautada pela lógica de restrições e permissões de acesso, inclusive ao código fonte, onerosas ou não, estabelecidas pelo regime jurídico clássico comercial (TAURION, 2004; RAYMOND, s/d).

${ }^{12}$ Repositório: banco de dados que permite a catalogação, o armazenamento e a busca dos objetos de informação e de aprendizagem.

${ }^{13}$ Objetos de aprendizagem: em inglês, learning objects. Unidades de software autocontidas, organizadas em determinada ordem segundo padrões de empacotamento, o que permite que os objetos sejam fechados em pacotes executáveis por diferentes sistemas e que os dados produzidos pelo usuário sejam rastreáveis por diferentes LMS (Dutra, 2008; Dutra \& TAROUCO, 2006).

${ }^{14}$ Metadados: descritores de identificação que podem ser pesquisados e compartilhados em ações educacionais, que trazem detalhes sobre autores, palavras-chave, assunto, versão, localização, regras de uso e propriedade intelectual, requisitos técnicos, tipo de mídia utilizada, nível de interatividade, entre outros, e permitem buscas rápidas em repositórios.

${ }^{15}$ Web 2.0: conjunto de funcionalidades tecnológicas que caracterizam uma web não apenas consumida (lida, acessada, pesquisada), mas também produzida pelos usuários, por meio de redes sociais e softwares como blogs e wikis.

${ }^{16}$ A computação baseada em nuvens se refere à forma de armazenamento da informação (software e todos os dados) em um servidor central, cujo acesso é feito por meio de navegador web, independente de dispositivos. 


\section{Referências bibliográficas}

Amaral, H. K. Desafios da capacitação de servidores públicos: contribuições da educação a distância. Apresentação no Encontro Nacional De Ead Para Rede De Escolas De Governo. Curitiba: Escola de governo do Paraná, set. 2008.

Dutra, Renato Luís de Souza. Encapsulamento e utilização de objetos de aprendizagem abertos SCORM para ensejar a avaliação formativa. 2008. Tese de doutorado apresentada ao Programa de Pós-Graduação em Informática na Educação da Universidade Federal do Rio Grande do Sul. Porto Alegre: UFRGS.

Dutra, Renato Luís de Souza; TArouco, Liane Margarida Rockenbach. Objetos de aprendizagem: uma comparação entre SCORM e IMS Learning Design. Revista Novas Tecnologias na Educação, v. 4, n. 1, 2006.

ENAP. Educação a Distância na ENAP - Riscos e Oportunidades. Relatório Final de Grupo de Trabalho. Brasília: set. 2009.

. Projeto para Implementação na ENAP do Ambiente Virtual "Moodle". Relatório Final de Grupo de Trabalho . Brasília: abr. 2008. . Referenciais orientadores da proposta educacional da ENAP. Brasília: 2010.

EduCAusE Learning Initiative (ELI) and the New Media Consortium (NMC). 2010 Horizon Report. Austin, TX: The New Media Consortium, 2010.

FILATro, Andrea. Learning design como fundamentação teórico-prática para o design instrucional contextualizado. 2008. Tese de doutorado apresentada à Faculdade de Educação da USP. Hase, S.; KenYon, C. From andragogy to heutagogy. Austrália: Southern Cross University, 2000. Litto, F. M.; Formiga, M. Educação a distância: o estado da arte. São Paulo: Pearson Education, 2008.

RaYMOND, Eric S. A catedral e o bazar. Disponível em: <http://www.geocities.com/ CollegePark/Union/3590/pt-cathedral-bazaar.html> Acesso em: 06 mar. 2008.

SIEMENS, G. Connectivism: a learning theory for the digital age. In: International Journal of Instructional Technology and Distance Learning, 2(1), 2004.

SiQueIRA, S. W. M. EDUCO: modelando conteúdo educacional. 2005. Tese de Doutorado apresentada ao Programa de Pós-graduação em Informática da PUC-Rio.

TAрsсотт, D. Geração digital. São Paulo: Makron Books, 1999.

TAurion, Cezar. Software livre: potencialidades e modelos de negócio. Rio de Janeiro: BRASPORT , 2004.

WELLER, M. Virtual learning environments: using, choosing and developing your VLE. New York: Routledge, 2007. 


\section{Resumo - Resumen - Absctract}

\section{Ambientes virtuais de aprendizagem: desafios de uma escola de governo} Andrea Filatro e Natália Teles da Mota

Este estudo apresenta informações que buscam subsidiar gestores e tomadores de decisão no processo de contratação de solução tecnológica especializada para a gestão da aprendizagem e do conhecimento, que possibilite o desenvolvimento, implementação e oferta de eventos de aprendizagem - a distância, presenciais ou mistos. A síntese aqui apresentada consolida as discussões do Grupo de Trabalho "Ambientes Virtuais de Aprendizagem" (GT-AVA) realizadas no âmbito da Escola Nacional de Administração Pública (ENAP). Fundamenta-se em uma série de debates interdisciplinares promovidos internamente pelo Grupo em 2010, resultando na construção de três cenários possíveis para o quadriênio 2011-2014, no que tange à infraestrutura tecnológica e implicações pedagógicas para a oferta de ações de aprendizagem, disseminação de informações e integração de recursos. Segue-se uma seção de considerações relativas aos fatores críticos a serem considerados para que a solução tecnológica adotada possa corresponder, em médio ou longo prazo, às demandas metodológicas, tecnológicas e jurídicas emergentes.

Palavras-chave: ambientes virtuais de aprendizagem; plataformas tecnológicas para educação; cenários para oferta de EAD em organizações públicas

\section{Entornos virtuales de aprendizaje: desafíos de una escuela de gobierno}

\section{Andrea Filatro y Natália Teles da Mota}

En este artículo se presenta la información que busca subsidiar los administradores y encargados de adoptar decisiones en el proceso de contratación de una solución tecnológica especializada en la gestión del aprendizaje y los conocimientos necesarios para el desarrollo, aplicación y oferta de eventos de aprendizaje - a distancia, presencial o mixtos. El resumen presentado aquí consolida las discusiones interdisciplinares del Grupo de Trabajo de Entornos Virtuales de Aprendizaje (GT-AVA) que se llevaron a cabo en la Escuela Nacional de Administración Pública (ENAP). Se fundamenta en una serie de debates interdisciplinares promovidos internamente por el Grupo en 2010, lo que dio lugar a la construcción de tres escenarios posibles para 2011-2014, con respecto a la infraestructura tecnológica y alcances pedagógicos para la oferta de acciones de formación, difusión de información e integración de recursos. A continuación, se encuentra una de las secciones de las consideraciones sobre los factores críticos a considerarse, para que las soluciones tecnológicas adoptadas puedan responder, a medio o largo plazo, a las exigencias metodológicas, tecnológicas y jurídicas emergentes.

Palabras clave: Entornos virtuales de aprendizaje; plataforma tecnológica para la educación; los escenarios para oferta de educación a distancia en instituciones públicas

\section{Virtual Learning Environment: challenges for a School of Public Service} Andrea Filatro and Natália Teles da Mota

This study presents information that seek subsidize managers and decision makers in the process of hiring of technological solution specialist for the management of learning and knowledge to enable the development, implementation and offering of distance education, face to face courses or mixed events of learning. The summary presented here consolidates the discussions of Virtual Learning Environment Working Group (GT-AVA) carried out under the National School of Public Administration - ENAP). It is based on a series of interdisciplinary 
debates promoted internally by the group in 2010, resulting in the construction of three possible scenarios for 2011-2014, regarding the technological infrastructure for learning sharing, release of information and integration of resources. It concludes with a section of considerations related to critical factors to be considered in choosing an e-learning technological solution, in order to respond to emerging ethodological, technological and legal demands.

Keywords: virtual learning environments; technological platform for education; scenarios for supply of distance education in public institutions

Andrea Filatro

Doutora em Educação pela Universidade de São Paulo, consultora em educação a distância e especialista em design instrucional.Contato: afilatro@uol.com.br

Natália Teles da Mota

Especialista em Psicopedagogia Clínica e Institucional pela Universidade de Brasília, coordenadora didático-metodológica da Coordenação-Geral de Educação a Distância da ENAP. Contato: natalia.mota@enap.gov.br 